\title{
Influence of different conditions for tilt compensation on symptoms of motion sickness in tilting trains
}

Reprint from Research Bulletin, Vol. 47, No. 5,

$$
\text { pp. 525-535, } 1998
$$

Johan Förstberg, VTI

Evert Andersson, Royal Institute of Technology, Stockholm

Torbjörn Ledin, University Hospital, Linköping

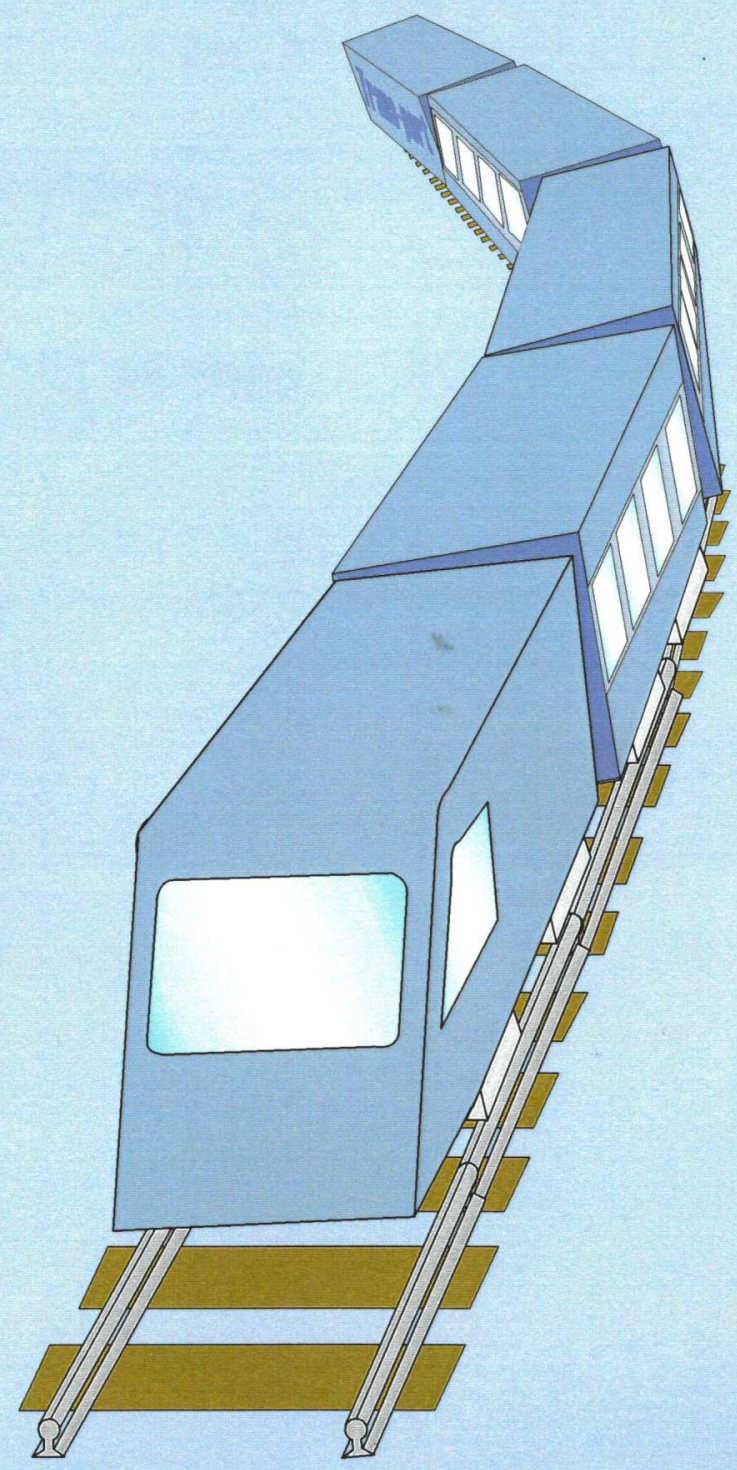

at 


\section{Influence of different conditions for tilt compensation on symptoms of motion sickness in tilting trains}

Reprint from Research Bulletin, Vol. 47, No. 5, pp. 525-535, 1998 Johan Förstberg, VTI

Evert Andersson, Royal Institute of Technology, Stockholm Torbjörn Ledin, University Hospital, Linköping 



\title{
Influence of different conditions for tilt compensation on symptoms of motion sickness in tilting trains
}

\author{
J. Förstberg, ${ }^{1, \star}$ E. Andersson ${ }^{2}$ and T. Ledin ${ }^{3}$ \\ ${ }^{1}$ Swedish National Road and Transport Research Institute, Railway Systems, Linköping, Sweden; \\ ${ }^{2}$ Royal Institute of Technology, Railway Technology, Stockholm, Sweden; and ${ }^{3}$ Department of ENT, \\ University Hospital, Linköping, Sweden
}

[Received 1 September 1997; Accepted 24 April 1998]

\begin{abstract}
Increased speeds of trains can be achieved by using tilting trains that decrease the lateral acceleration experienced by passengers on curves, thereby allowing trains to run typically $25-30 \%$ faster on existing curved track and maintaining good ride comfort. Unfortunately, motion sickness in tilting trains is a major problem for some passengers. To investigate the incidence of motion sickness and the extent to which different tilt compensation strategies influence its occurrence tests were conducted with a tilting train on a track with a large number of curves. Eighty healthy volunteers were studied, selected partly for their susceptibility. Three different cars were evaluated during 3 test days, with each test ride lasting about $3 \mathrm{~h}$. On four occasions per test ride, the subjects answered a questionnaire concerning activities during the ride, ride comfort, ability to work and read, vegetative symptoms, fatigue, sleepiness, nausea and well-being. Subjects estimation of average ride comfort and ability to work and read was good in all conditions. However, $10 \%$ of the test subjects reported various symptoms of motion sickness (SMS). A 55\% degree of tilt compensation of the lateral acceleration instead of the normal $70 \%$ reduced the symptoms of motion sickness incidence (SMSI) by $25-40 \%$. SMSI correlated poorly with motion doses, which integrates vertical or lateral acceleration but correlated well with roll acceleration motion dose $\left(r^{2}=0.43, p<0.001\right)$. For women, riding backward $(p<0.001)$ minimized SMSI, but men were insensitive to direction. Future railway design will have to optimize tilt systems by both minimizing motion sickness and avoiding excessive lateral acceleration or jerk. (c) 1999 Elsevier Science Inc.
\end{abstract}

KEY WORDS: Ride comfort, Motion sickness, High-speed tilting trains.

\section{INTRODUCTION}

Railway companies throughout the world are looking for ways of increasing train speeds and ride comfort. Because most countries have a significant mileage of curved track, measures must be taken to compensate for the lateral accelerations on curves if speed is to be increased without detracting from comfort. The construction of new railways with straighter tracks has been used in some countries, but many railway companies have found this method to be too expensive. A further alternative is to make car bodies of the train tilt inward on curves [3]. It is believed to be favorable to compensate for only parts of the centrifugal forces on the curves $[16,17]$. This enables trains to travel typically $25-30 \%$ faster on existing curved track. In Sweden, the preferred tilt compensation strategy method for the X2000 train has been to compensate for about $70 \%$ of the lateral acceleration on curves.

Many modes of transport are associated with the occurrence of motion sickness in susceptible individuals. These include tilting trains $[27,36]$. When this involves a pilot in a military jet aircraft, the implications are of course severe [1], but passenger discomfort in airplanes is by no means a negligible problem [4]. The problems are no less serious in space technology [8]. The most widely studied area of motion sickness is the naval area, where the importance of vertical low-frequency oscillations was identified [14,15,21-23]. Estimating the impact of different motion patterns on the occurrence of motion sickness has been the subject of many issues of work dealing with standardization $[5,18]$.

In regard to railways, passenger ride comfort and discomfort on curves have attracted much research $[2,6,9,10,16,20,33,34]$, but concerning motion sickness, a good understanding of the problem is still needed $[11,12,27,36]$. A $100 \%$ compensation has been found to be provocative for motion sickness in the Advanced Passenger Train test in 1984 [7], and a recommendation for a tilt compensation of two thirds $(67 \%)$ has been given $[16,17]$.

To investigate the incidence of motion sickness symptoms and the extent to which different compensation strategies influence the occurrence of such discomfort, a full-scale test was conducted with the Swedish tilting train X2000 in June 1995. The results of three different compensation conditions were reported [11]. Earlier, three other conditions had been tested in November 1994 [11].

\section{MATERIALS AND METHODS}

\section{Test Subjects}

Healthy volunteers were chosen, partly for their high subjective sensitivity to nausea. The experiment was conducted in June 1995 using about 80 subjects who were mostly students from Linköping University aged 20-30 years but also included some employees of the Swedish National Road and Transport Research Institute and Linköping University Hospital.

* Address correspondence to: J. Förstberg, Swedish National Road and Transport Research Institute, Railway Systems, SE-58195 Linköping, Sweden. E-mail: johan.forstberg@vti.se 
TABLE 1

DATA FOR TEST SUBJECTS IN THE TEST GROUPS

\begin{tabular}{lcccc}
\hline & $\begin{array}{c}\text { Test Group 1 } \\
\text { in Car 1 }\end{array}$ & $\begin{array}{c}\text { Test Group 2 } \\
\text { in Car 2 }\end{array}$ & $\begin{array}{c}\text { Test Group 3 } \\
\text { in Car 4 }\end{array}$ & Total \\
\hline Number of Test Subjects & 22 & 30 & 20 & 72 \\
Percentage Female & 45 & 50 & 45 & 47 \\
Mean Age (y) & 24 & 25 & 25 & 25 \\
Mean Sensitivity, Female & 4.2 & 3.6 & 3.0 & 3.6 \\
Mean Sensitivity, Male & 2.7 & 2.6 & 2.5 & 2.6 \\
Mean Sensitivity & 3.3 & 3.1 & 2.7 & 3.1 \\
\hline
\end{tabular}

"Sensitivity rated on a scale from 1 (no sensitivity) to 7 (very high sensitivity).

In earlier experiments [11], women had reported two to three times more symptoms of motion sickness than men. Therefore, almost identical proportions of women and men in all test conditions and groups were used in this test (Table 1). The distribution of self-rated sensitivity to motion sickness is shown in Table 2 .

The test subjects were instructed to read or work during the test ride. They were also instructed to ride either forward or backward during all test runs, which meant changing seat and direction before the return trip. They could see each other and in some cases talk to each other. About three quarters of the test subjects occupied window seats. No one became so nauseated so that it influenced another subjects.

\section{Definitions}

Tilt angle, tilt speed and tilt acceleration are the corresponding angle, speed, and acceleration with which the tilt system can rotate the car body with respect to the track plane. Roll angle, roll speed and roll acceleration are the corresponding angle, speed, and acceleration with which the car body rotates with respect to the horizontal plane.
TABLE 2

PERCENTAGE OF THE MALE AND FEMALE SUBJECTS' SELF-RATED SENSITIVITY TO MOTION SICKNESS

\begin{tabular}{lrrrrrrrr}
\hline & \multicolumn{7}{c}{ Rated Sensitivity } \\
\cline { 2 - 8 } & 1 & 2 & 3 & 4 & 5 & 6 & 7 \\
\hline Percentage Male & 27 & 21 & 34 & 13 & 5 & 0 & 0 \\
Percentage Female & 8 & 30 & 12 & 25 & 20 & 5 & 0 \\
\hline
\end{tabular}

\section{Track Characteristics}

The test runs were conducted on tracks with large numbers of curves between Järna (about $47 \mathrm{~km}$ south of Stockholm) and Linköping (about $225 \mathrm{~km}$ south of Stockholm) (Fig. 1). The test track is about $180 \mathrm{~km}$ long, with permitted speeds of 180-200 $\mathrm{km} / \mathrm{h}$ for about $85 \%$ of the track length. Curve radii varied mostly within the range of 1000-1250 m. A section between Linköping and Norrköping has some curves with radii of $440-800 \mathrm{~m}$, with speeds limited to $125-145 \mathrm{~km} / \mathrm{h}$. The test track was divided into two segments at the station of Katrineholm, thereby allowing evaluation of the results in four sections (test parts). The stations of Norrköping and Katrineholm were passed at low speed.

\section{Tilt System and Test Train}

A car body tilt system is designed to lower the centrifugal forces (lateral acceleration) experienced by the passenger by tilting the car body inward on curves. The design is intended to enhance ride comfort and has, in principle, no effects on safety or track forces. On curves, a tilting train may travel at speeds typically 25-30\% faster than a normal non-tilting train, if no other comfort or safety limits are violated [2,3]. A schematic sketch of the tilt system is shown in Fig. 2.

The test train used in this experiment was an X2000 train, consisting of a power car and five passenger cars. The test subjects

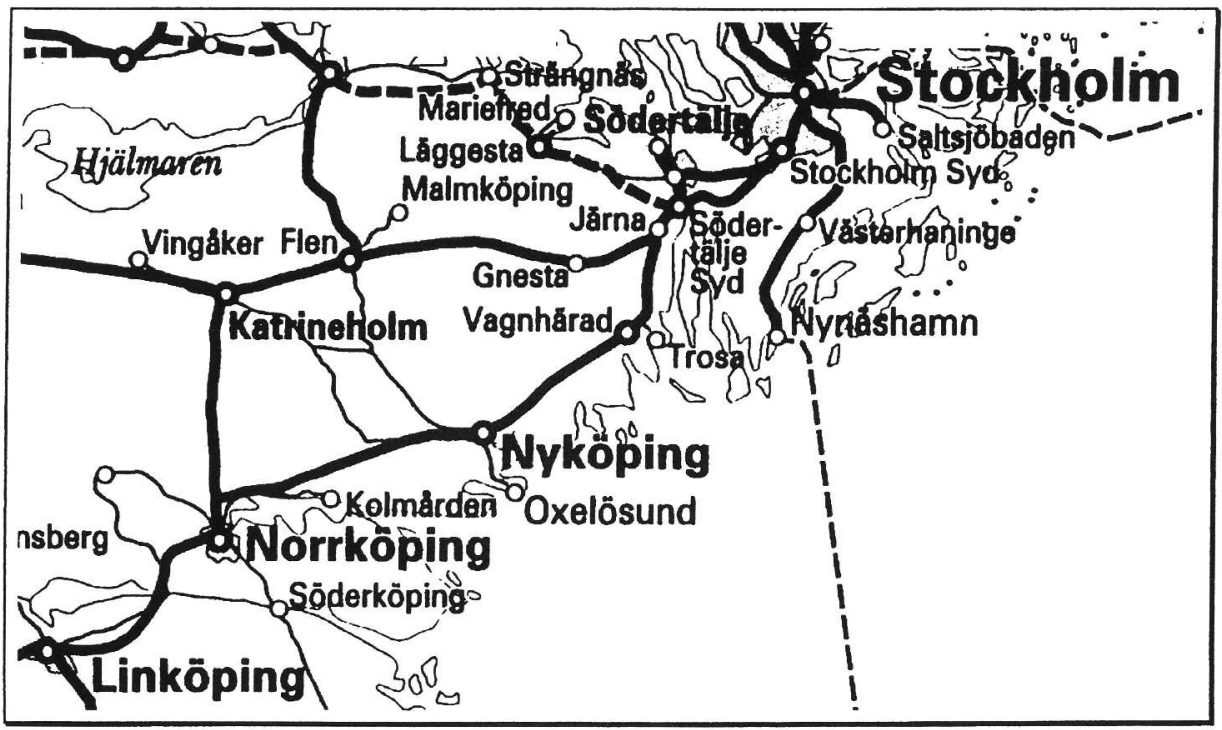

FIG. 1. Map showing the railway lines (thick lines) between Stockholm and Linköping. Järna is about $47 \mathrm{~km}$ southwest from Stockholm, Katrineholm about $134 \mathrm{~km}$ and Linköping about $225 \mathrm{~km}$. 


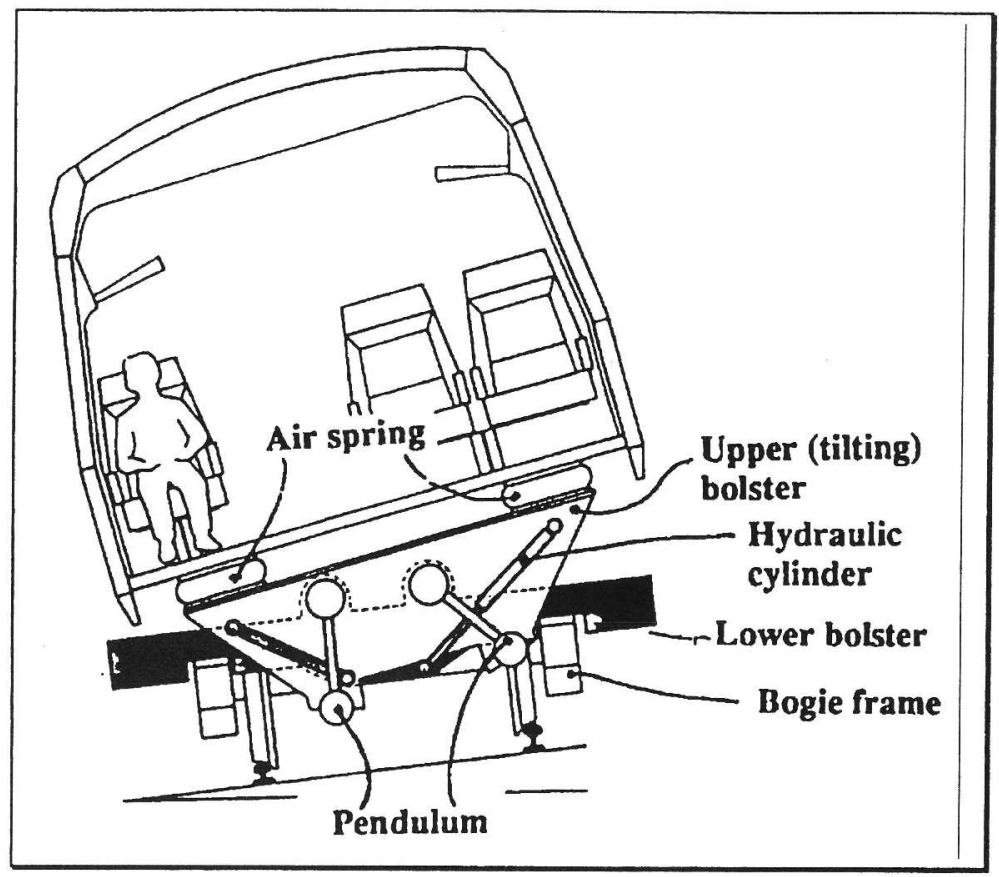

FIG. 2. Car body tilt function in the X2000. Hydraulic cylinders rotate the upper bolster in respect to the lower bolster. Maximum angle between the two bolsters is about 8 degrees. Because of the flexibility in the suspension system, the effective tilt angle is about 6.5 degrees. (From [3].)

were seated in cars 1, 2 and 4. Measurement equipment was located in the bistro car (Fig. 3).

\section{Tested Compensation Strategies}

Three different tilt compensation strategies (A, F and G) were tested in this experiment (Table 3). Earlier, four different conditions had been tested with a generally positive outcome for low tilt compensations [11]. The independent parameters for the tilt system were degree of tilt compensation, limitation of tilt speed and/or acceleration. These limitations were aimed not to interfere with the tilt motion necessary to tilt the car body in time but to reduce tilt motions caused by track irregularities.

The design during this experiment was that of a Latin square This means that the test subjects were seated in the same car during the whole test and the different test conditions were rotated as in Table 4. This design was selected to minimize differences in age, gender and sensitivity in the different test groups and also to minimize influence of the cars and its position in the train.

\section{Evaluation}

Before the test ride, the subjects answered a questionnaire concerning age, sex, rated subjective sensitivity to motion sickness and well-being. Each test ride lasted about $3 \mathrm{~h}$. After each quarter of the test ride (about $45 \mathrm{~min}$ ), the subjects answered another questionnairê concerning activity, ride comfort, comfort disturbances due to high levels of accelerations, jerks (rate of change of acceleration), jolts, ability to work/read and vegetative symptoms such as drowsiness, pallor, salivation, fatigue, sleepiness, dizziness

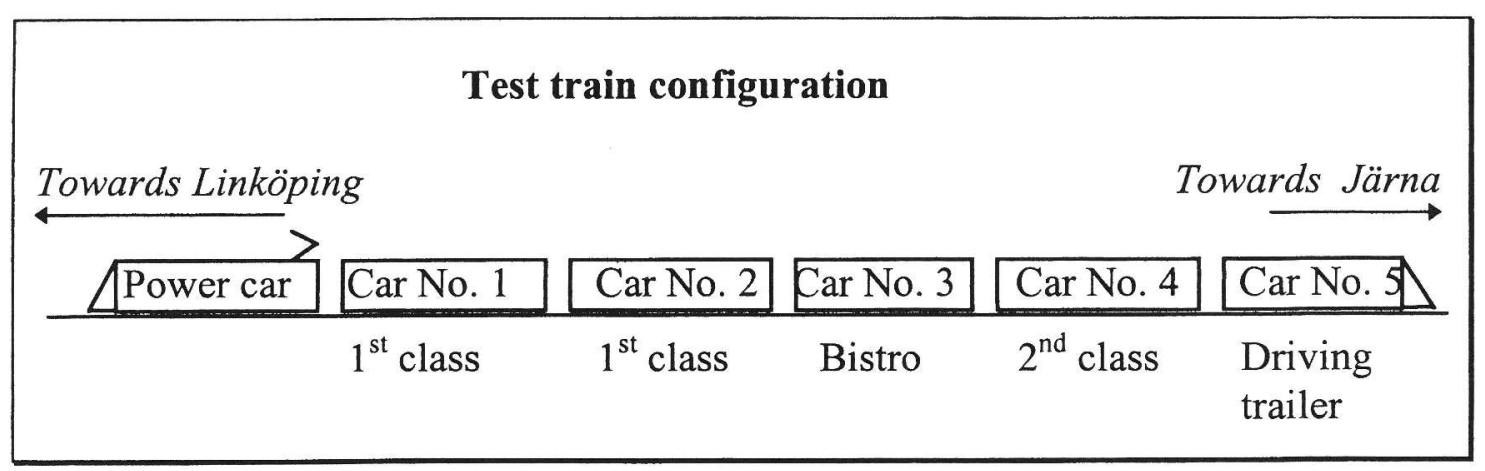

FIG. 3. Test train configuration. Test subjects were seated in cars 1,2 and 4 
TABLE 3

VARIATION OF PARAMETERS USED IN THE TILT SYSTEM DURING THE EXPERIMENTS

\begin{tabular}{lccccc}
\hline $\begin{array}{c}\text { Test } \\
\text { Conditions }\end{array}$ & $\begin{array}{c}\text { Speed } \\
(\%)\end{array}$ & $\begin{array}{c}\text { Tilt } \\
\text { Comp } \\
(\%)\end{array}$ & $\begin{array}{c}\text { Car Body } \\
\text { Tilt Speed } \\
\text { Limit }(\%)\end{array}$ & $\begin{array}{c}\text { Car Body Tilt } \\
\text { Acceleration } \\
\text { Limit }\left(\% \mathrm{~s}^{2}\right)\end{array}$ & $\begin{array}{c}\text { Lateral } \\
\text { Acceleration } \\
\text { in Car } \\
\text { Body }^{b}\left(\mathrm{~m} / \mathrm{s}^{2}\right)\end{array}$ \\
\hline $\mathrm{A}$ & +25 & 70 & 4 & No limit & 0.6 \\
$\mathrm{~F}^{d}$ & +25 & 55 & 4 & 4 & 0.8 \\
$\mathrm{G}^{d}$ & +25 & 55 & 2.3 & No limit & 0.8
\end{tabular}

${ }^{a}$ Compared with normal nontilting trains.

b Typical maximum values.

$c$ The car body tilt acceleration was not limited by the tilt system. Due to inertia of the car body and stiffness of the suspension and dampers, the maximum car body angular acceleration is estimated to be about $10 \% \mathrm{~s}^{2}$.

${ }^{d}$ Conditions A-D were tested in earlier experiments. Condition E was planned but never realized with limited car body tilt acceleration and $70 \%$ compensation.

and nausea. They also scored their well-being on a five-point scale (I feel alright, I do not feel quite well, I feel rather unwell, I feel bad, I feel very bad), both at the beginning of the journey and after each test part. The physical parameters of the train ride were recorded for analysis of possible relations between accelerations (linear and angular) in the train and symptoms of motion sickness.

In the evaluation of motions of the train, the concept of motion dose was used:

$$
\operatorname{MSDV}_{Z}=\left[\int_{0}^{T} a_{w}^{2}(t) d t\right]^{1 / 2}\left(\mathrm{~m} / \mathrm{s}^{1.5}\right)
$$

where $\operatorname{MSDV}_{Z}$ is the motion sickness dose value and $a_{1,}(t)$ is frequency-weighted acceleration. Weighting filter, $w_{f}$, has maximal transmission between 0.1 and $0.3 \mathrm{~Hz}$. The percentage of persons who may vomit $=K_{m} \times \operatorname{MSDV}_{Z}(\%)$ and $K_{m}=1 / 3$ for a mixed population of unadapted male and female adults $[14,18]$. Also their rating of well-being, or Illness Rating (IR: 0, I felt all right; 1, I felt slightly unwell; 2, I felt quite ill; 3, I felt absolutely dreadful. IR $=1 / 50 \times \operatorname{MSDV}_{Z}$ [14,21]), was adopted in this experiment. The weighting function $\left(w_{f}\right)$ [18] has been used for all calculations on motion dose from vertical, lateral and roll accelerations.

\section{Incidence of Motion Sickness Symptoms}

The definition of symptoms of motion sickness (SMS) was that the subjects reported one of the following symptoms: dizziness, nausea or I do not feel fine. If the subject did not feel fine at the beginning of the test run, he/she was omitted from evaluation.

TABLE 4

DESIGN OF THE EXPERIMENT. EACH GROUP WAS TESTED OVER A PERIOD OF 3 DAYS WITH DIFFERENT CONDITIONS TO MINIMIZE BIAS BECAUSE OF DIFFERENCES IN SENSITIVITY ETC.

\begin{tabular}{lccc}
\hline & Day 1 & Day 2 & Day 3 \\
\hline Car 1 & A & F & G \\
Car 2 & G & A & F \\
Car 4 & F & G & A
\end{tabular}

TABLE 5

COMPARISON OF ESTIMATED RIDE COMFORT. PERCENTAGE OF SUBJECTS COMPLAINING OF COMFORT DISTURBANCES DUE TO LOW-FREQUENCY LATERAL ACCELERATIONS AND ESTIMATED WORKING/READING ABILITY

\begin{tabular}{lccc}
\hline & $\begin{array}{c}\text { Estimated } \\
\text { Ride Comfort }\end{array}$ & $\begin{array}{c}\text { Comfort Disturbances } \\
\text { from Lateral } \\
\text { Accelerations (\%) }\end{array}$ & $\begin{array}{c}\text { Estimated Working/ } \\
\text { Reading Ability }\end{array}$ \\
\hline Condition A & 4.1 & 58 & 4.1 \\
Condition F & 4.2 & 54 & 4.1 \\
Condition G & 4.2 & 54 & 4.2 \\
\hline
\end{tabular}

"On a five-point scale from very bad (1) to very good (5).

"Percentage of the test subjects who reported this kind of discomfort. No statistically significant differences were found.

Incidence of $S M S$ (SMSI) is then calculated as the sum of reported SMS from all subjects and over all test parts, divided by the total sum of subjects and test parts.

\section{Statistical Evaluation}

The number of SMS in the above parameters was compared between tested conditions using the chi-square test [32].

\section{RESULTS}

\section{Ride Comfort and Rated Working/Reading Ability}

Test subjects reported good ride comfort (in average 4.1-4.2 on a five-point scale) and about the same level of comfort disturbances in all conditions. They also rated their ability to read and work as about $4.1-4.2$ for these conditions (Table 5).

\section{Symptoms of Motion Sickness}

In the experiment, the two tested conditions with $55 \%$ compensation (F and $\mathrm{G}$ ) showed a lower SMSI than condition A, but only the condition $\mathrm{G}$ was significantly lower at the $5 \%$ level. The reduction of SMSI was $25-40 \%$ compared with condition A (Table 6).

A chi-square analysis shows that the differences between the number of test subjects experiencing SMS in conditions A, F and $\mathrm{G}$ is significant on the $10 \%$ level $\left(\chi^{2}=4.94, d f=2, p \leq 0.08\right)$, but the difference between $\mathrm{A}$ and $\mathrm{F}$ is significant on the $5 \%$ level $\left(\chi^{2}=4.73, d f=1, p \leq 0.029\right)$.

Differences in gender. Differences in the reported symptoms of motion sickness and discomfort among gender are shown in Figs. 4 and 5 . Women were found to score about two to three times as high as the men on the items of nausea ("I don't feel well" and

TABLE 6

PERCENTAGE OF SUBJECTS WITH SYMPTOMS OF MOTION SICKNESS (SMSI) DURING THE TESTS, GIVEN AS INCIDENCE PER TEST PERIOD (QUARTER OF THE 3-H TEST SESSION)

\begin{tabular}{lcc}
\hline Condition & SMSI (\%) & $\begin{array}{c}\text { Confidence Interval } \\
\text { Approx. } 95 \%\end{array}$ \\
\hline A & 14.5 & $10.5-18.4$ \\
F & 10.7 & $7.1-14.3$ \\
G & 8.5 & $5.3-11.6$ \\
\hline
\end{tabular}




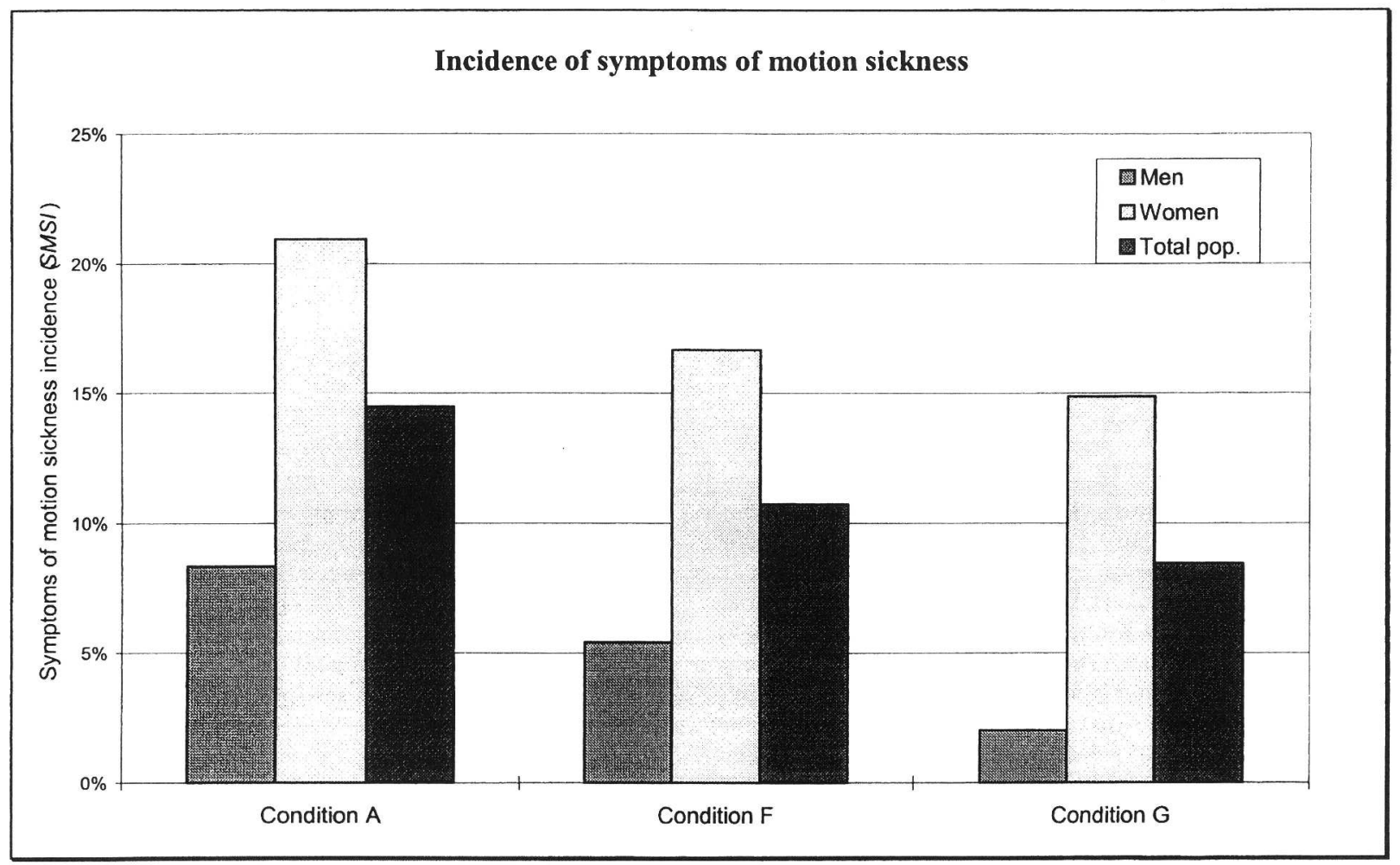

FIG. 4. Differences in SMSI for men, women and the total group of test subjects.

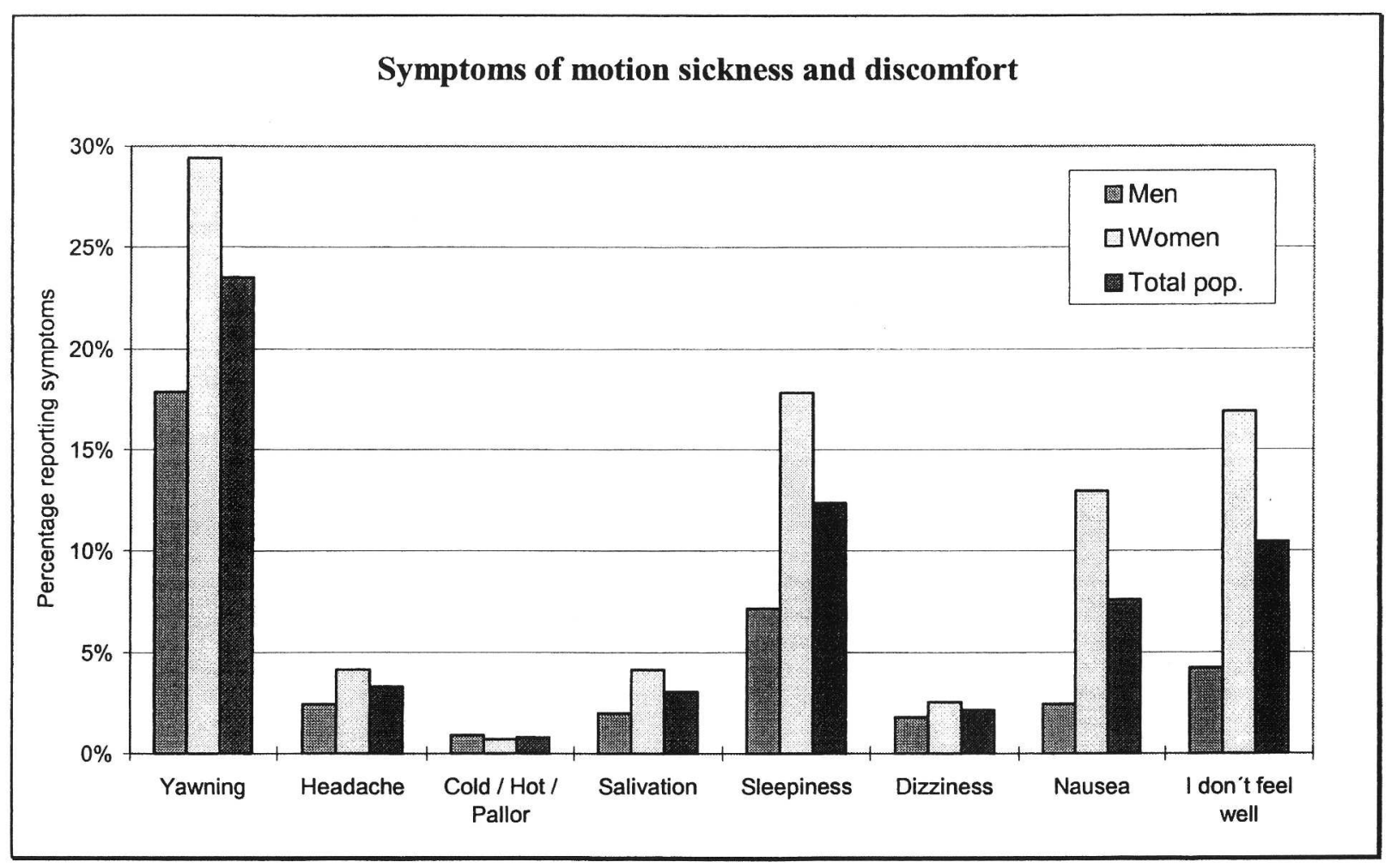

FIG. 5. Differences in symptoms of motion sickness and discomfort for men, women and the total group of test subjects summarized over conditions $\mathrm{A}, \mathrm{F}$ and $\mathrm{G}$. 
TABLE 7

SMS AND SMSI FOR TRAVELING FORWARD OR BACKWARD FOR MALE AND FEMALE SUBJECTS SITTING AT A WINDOW SEAT OR NOT, SUMMARIZED OVER THE CONDITION A, G AND F

\begin{tabular}{|c|c|c|c|c|c|c|c|c|}
\hline & \multicolumn{4}{|c|}{ Window Seat } & \multicolumn{4}{|c|}{ Non-window Seat ${ }^{a}$} \\
\hline & Male For. & Male Back. & Female For. & Female Back. & Male For. & Male Back. & Female For. & Female Back. \\
\hline$S M S$ & 10 & 14 & 33 & 14 & () & 0 & 21 & 7 \\
\hline SMSI & $6 \%$ & $7 \%$ & $20 \%$ & $10 \%$ & $0 \%$ & $0 \%$ & $38 \%$ & $11 \%$ \\
\hline$x^{2}$ & \multicolumn{2}{|c|}{0.06} & \multicolumn{2}{|c|}{4.77} & \multicolumn{2}{|c|}{-} & \multicolumn{2}{|c|}{10.3} \\
\hline$p$ & \multicolumn{2}{|c|}{ NS } & \multicolumn{2}{|c|}{0.029} & \multicolumn{2}{|c|}{-} & \multicolumn{2}{|c|}{0.001} \\
\hline
\end{tabular}

${ }^{a}$ Only about $25 \%$ occupied a non-window seat

For., forward; Back., backward.

"SMSI"; Fig. 5). The women's SMSI score is about $12 \%$ higher than for men (Fig. 4). Figure 5 also shows variations in other symptoms of motion sickness.

Riding forward or backward. Women show a large variation in $S M S I$ with the direction of travel. They scored significantly less SMSI when riding backward (Table 7 . For men, there was very little difference. Being seated at a window may affect women but not men regarding SMSI.

Correlation between self-rated sensitivity and symptoms. The subjects rated their sensitivity to motion sickness before the test runs on a seven-point scale from 1 (none) to 7 (very large). Figure 6 shows the percentage of subjects with a certain rated sensitivity experiencing SMS. For the regression line for men and women together, the regression coefficient is high $\left(r^{2}=0.95\right)$. The distribution of male and female subjects is shown in Table 2 .
Time dependence. Analyzing the time pattern of SMSI, the incidence of discomfort was highest at the first and last inquiries during the 3-h ride (Fig. 7). According to the motion dose hypothesis of Lawther and Griffin [21], the SMSI would increase during the course of the ride. Furthermore, the SMSI pattern in the course of time is significantly different from a pattern with an equal proportion of SMSI in each test part $\left(\chi^{2}=10.98, d f=3, p \leq\right.$ 0.012 ).

\section{Motion Environment}

In evaluating the motion environment of vertical, lateral and roll accelerations, the weighting filter, $w_{f}[18]$, has been used for calculating the corresponding motion doses.

Figure 8 shows both the motion dose from lateral accelerations

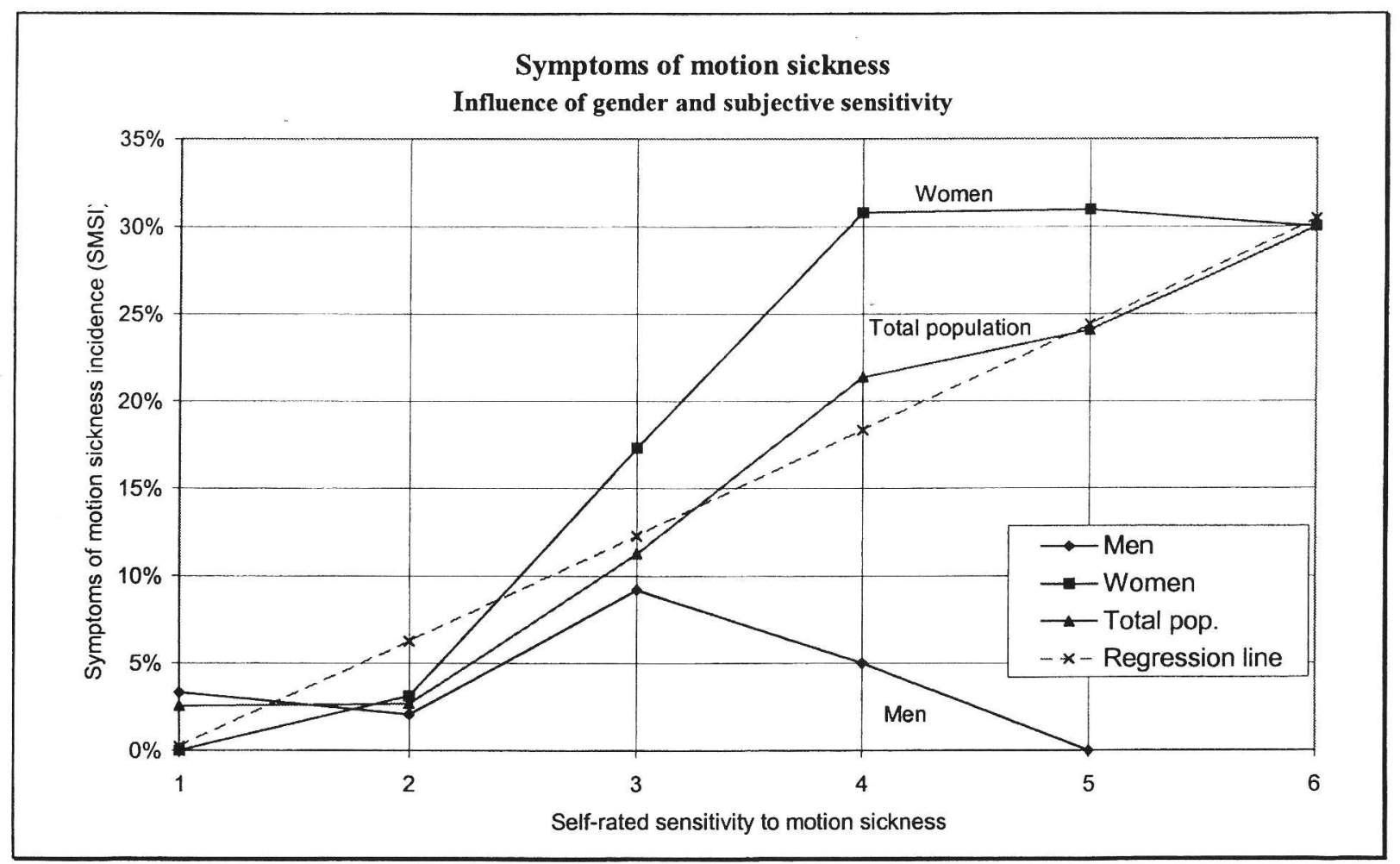

FIG. 6. Percentages (SMSI) of the subjects experiencing an SMS as a function of self-rated sensitivity. Five percent of the male subjects rated their sensitivity as 5 or 6 . The corresponding proportion for female subjects is $25 \%$. 


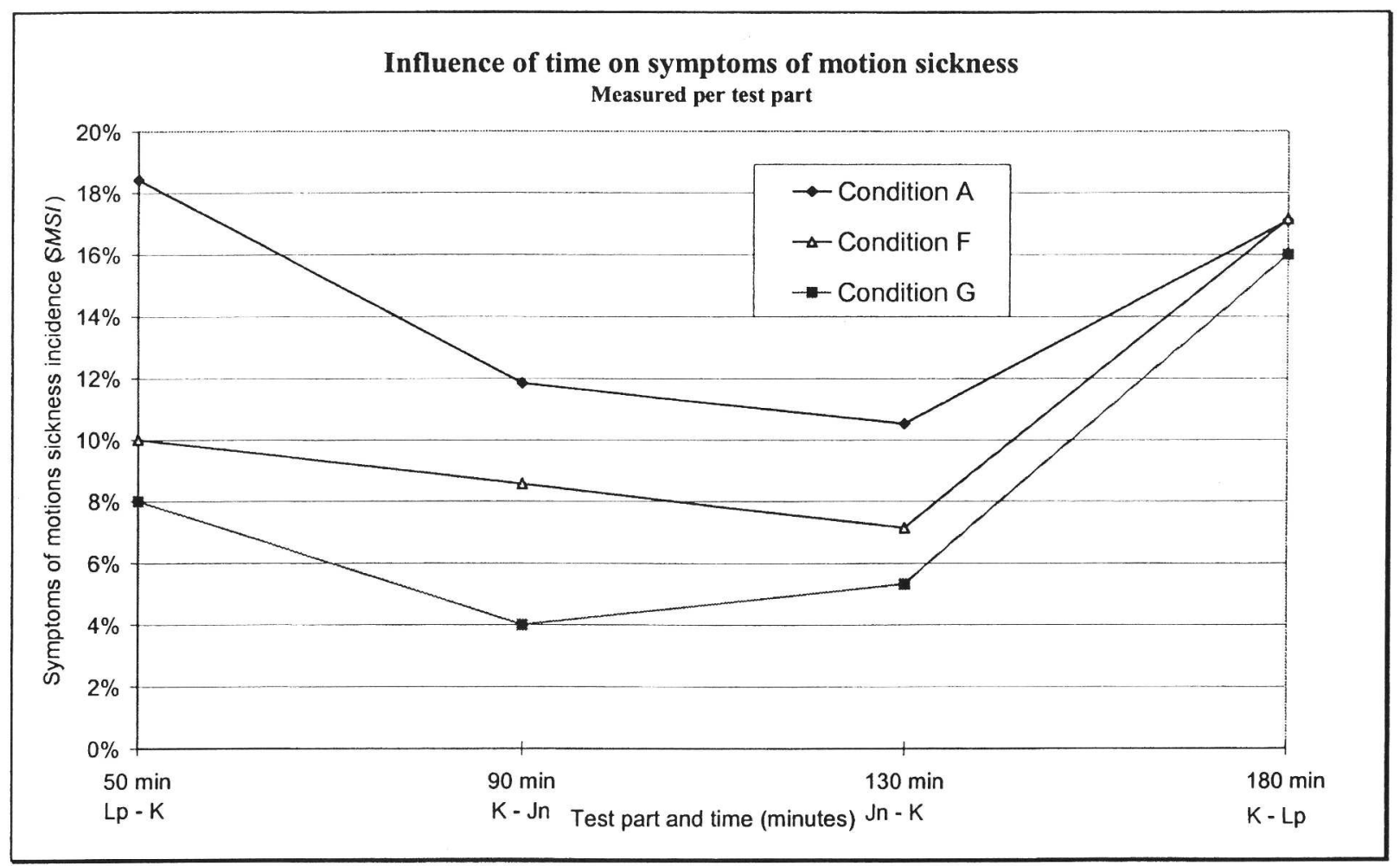

FIG. 7. SMSI as a function of traveled time and test part.

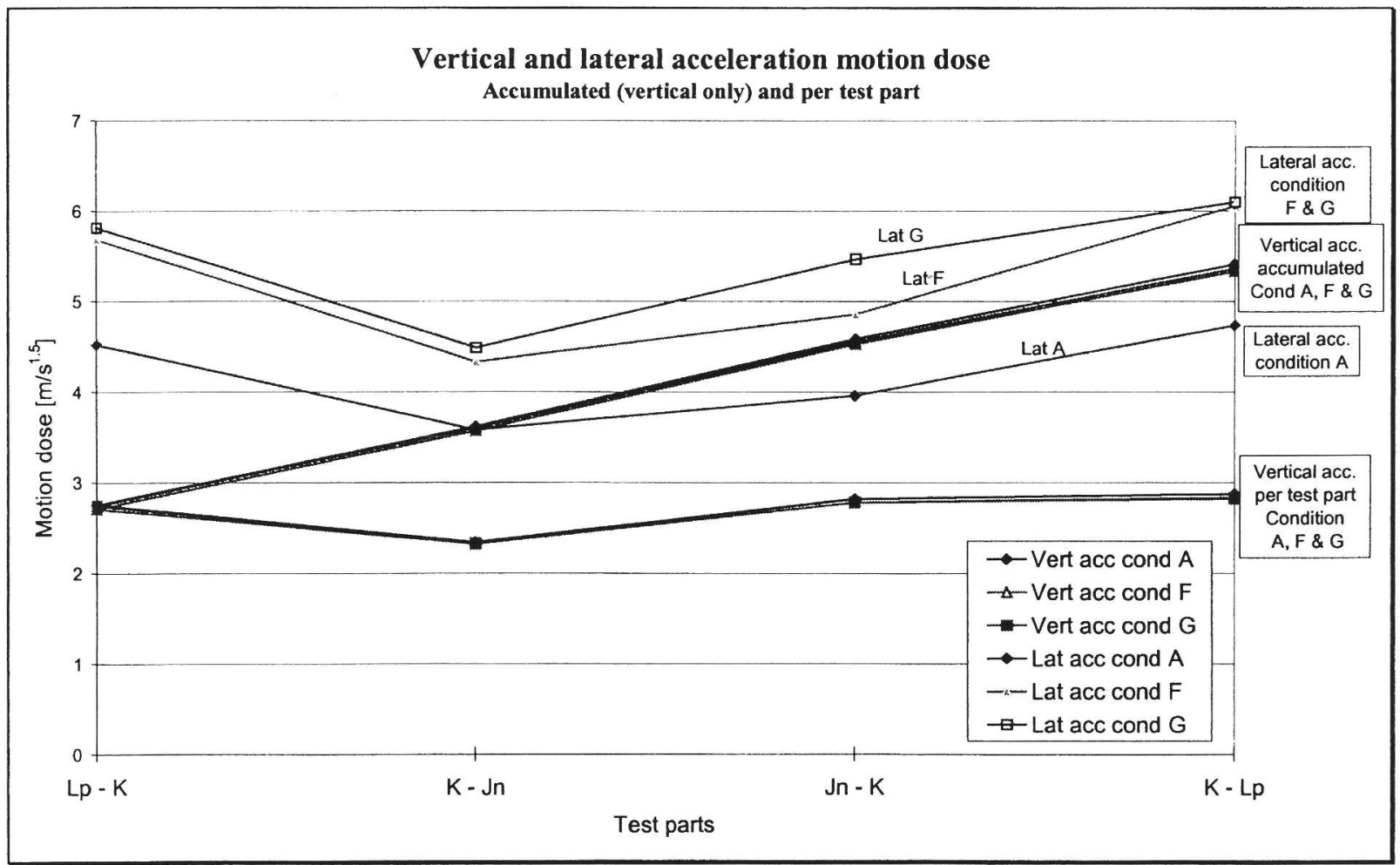

FIG. 8. Motion dose from vertical acceleration accumulated over the test parts and lateral and vertical motion dose per test part. 


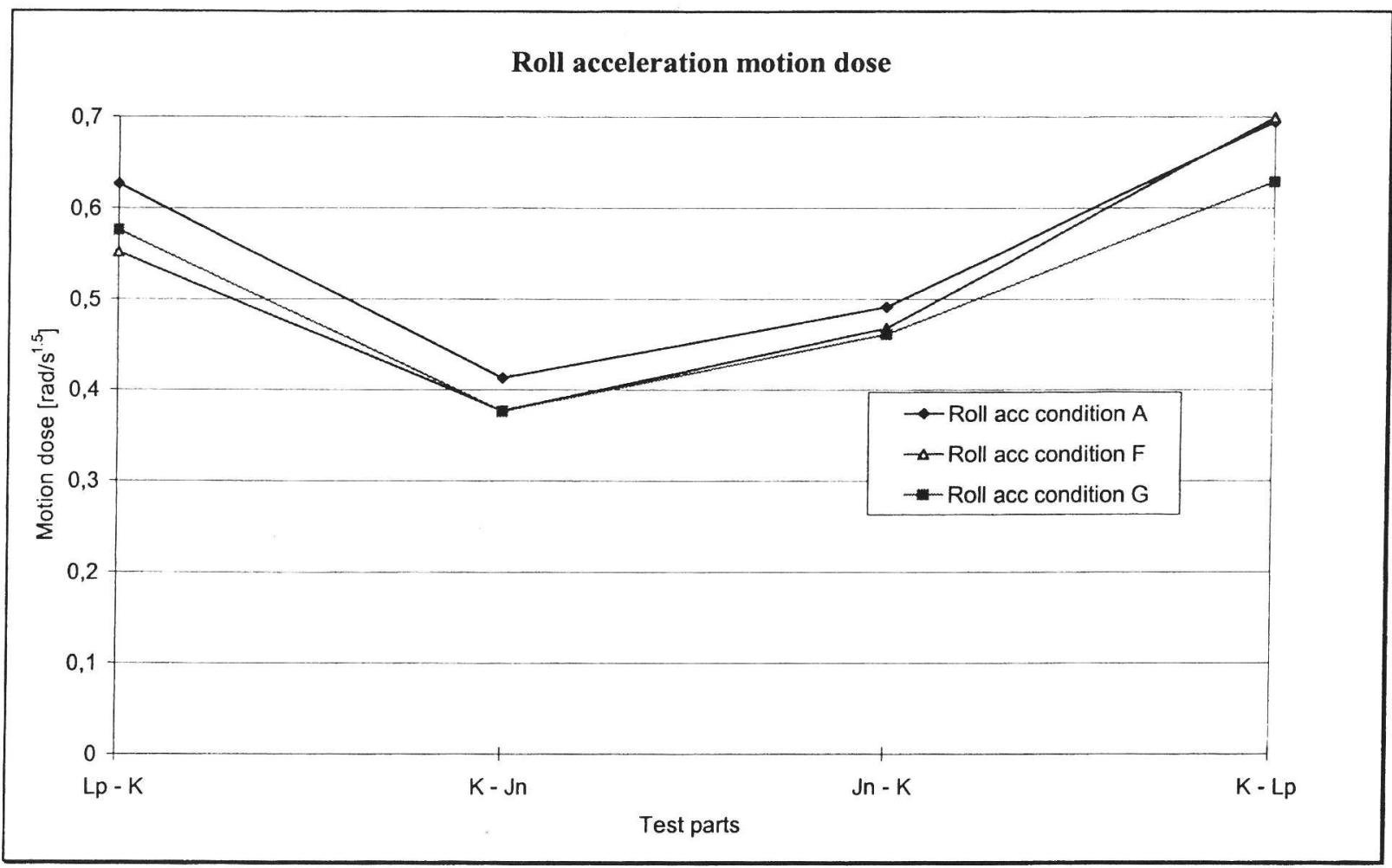

FIG. 9. Motion dose from roll accelerations shown per test part

and from vertical accelerations. The motion dose for vertical accelerations is displayed both as accumulated and per part. For motion doses generated from vertical accelerations, the differences between conditions $\mathrm{A}, \mathrm{F}$ and $\mathrm{G}$ are very small, suggesting that the differences in motion dose from vertical accelerations are not responsible for the differences in actual SMSI for these conditions.

The motion dose from lateral accelerations shows an upsidedown picture. Condition A has the lowest motion dose values and condition $\mathrm{G}$ the highest. This corresponds well to the observation that condition A has a higher compensation level of the lateral acceleration than the other two conditions. The motion dose on test part 1 and 4 is higher than on the two middle parts, indicating that the test track between Linköping and Katrineholm is more severe in both directions in terms of nausea.

Figure 9 shows the motion dose of roll accelerations, where the condition A now displays higher motion dose values than the other two. The motion dose (due to roll acceleration) for test parts 1 and 4 shows higher values than the other two test parts, similar to the lateral acceleration motion dose. However, roll motion doses for condition A have greater values than the other two conditions. This pattern is similar to the SMSI pattern in Fig. 7. This may indicate that roll acceleration motion dose is one of the prime causes of motion sickness in this case.

Regression analysis. To analyze the influence of vertical, lateral and roll accelerations on symptoms of motion sickness, a regression analysis was performed. This analysis shows that the lateral and vertical accelerations do not significantly contribute to the explanation of SMSI. If these two factors are included, they will appear with a negative sign, which is physically impossible. A linear regression model (SMSI $=\alpha+\beta \times$ roll acceleration motion dose) suggests an influence of roll acceleration motion dose on
SMSI for the total population with a statistical significance of $F(1,34)=25.24$ and $p<0.001$ (Table 8).

The corresponding regression analysis for female and male subjects shows that women have a greater sensitivity than the total population and men less sensitivity, but for men the regression coefficient is rather weak (Fig. 10).

\section{DISCUSSION}

The mechanisms of motion sickness are not well known. The most popular hypothesis is the sensory conflict theory [4,28-30], whereas others have advocated that the motion sickness response is a protective function for the integrity of the body [26,35]. It seems clear that the vestibular organs are a necessary part of the reaction [26].

Vertical accelerations alone within a frequency range of 0.1 $0.3 \mathrm{~Hz}$ have proved to be provocative for motion sickness $[14,15,21,24]$, among others. Lawther and Griffin [21] suggested

TABLE 8

REGRESSION COEFFICIENTS FOR THE ROLL ACCELERATION INFLUENCE ON SMSI, WITH 95\% CONFIDENCE INTERVAL, VALID FOR THE TOTAL POPULATION

\begin{tabular}{lrcccc}
\hline & Coefficient & Std-error & $p$ & $\begin{array}{c}\text { Lower } \\
\text { 95\% Conf. } \\
\text { Interval }\end{array}$ & $\begin{array}{c}\text { Upper } \\
\text { 95\% Conf. } \\
\text { Interval }\end{array}$ \\
\hline$\alpha$ (Constant) & -0.055 & 0.034 & 0.116 & -0.12 & 0.014 \\
$\beta$ (Roll Acceleration) & 0.317 & 0.063 & $<0.001$ & 0.189 & 0.445 \\
\hline
\end{tabular}




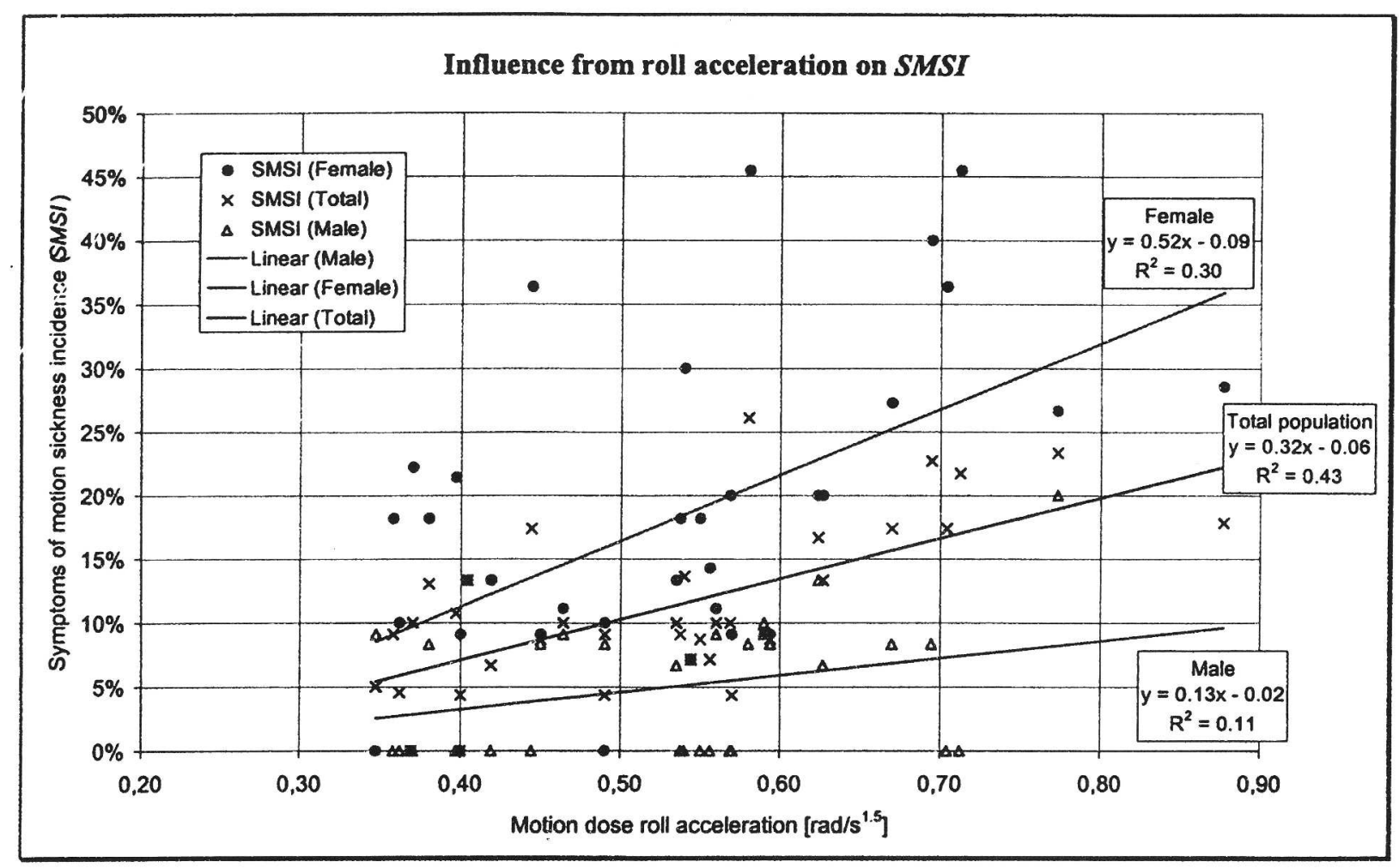

FIG. 10. Regression curves from roll acceleration motion dose on SMSI for female, male and total population.

the concept of a cumulative motion dose for the evaluation and prediction of motion sickness at sea. This corresponds fairly well with earlier results [24]. A scale of corresponding illness, IR, has also been suggested [21]. In this study, if $90 \%$ of subjects reported "I feel alright" (this means that $10 \%$ reported not feeling well), this would give an $S M S I \geq 10 \%$ and would correspond to an IR of about 0.1 .

Horizontal accelerations (longitudinal and lateral) have recently been shown to be about twice as provocative as vertical accelerations. (Golding et al. [13] suggested that longitudinal acceleration is twice as provocative as vertical acceleration for a person sitting upright. The $K_{m}$ in the motion dose formula is changed to $1.41 \times K_{m}$. Lateral acceleration is about as provocative as longitudinal acceleration.) McCauley et al. [24] found no evidence that roll or pitch motion combined with a vertical acceleration altered the nauseogenicity of vertical accelerations. They used fairiy high levels of vertical accelerations, resulting in a motion sickness incidence (vomiting incidence in a 2-h test) of $30-50 \%$. Wertheim et al. [37] conducted several experiments to refute McCauley et al.'s hypothesis [24]. They showed that roll and pitch motion alone can be nauseogenic and also that a small amplitude of vertical acceleration amplifies nauseogenicity of the roll/pitch motion.

In this study, the vertical and lateral accelerations are concurrent factors with roll acceleration instead of independent factors. Also, icll velocity and roll acceleration are highly correlated. From the performed tests anid evaluations, it is difficult to separate their combined influence, but it seems hiat moll acceleration motion dose has the greatest influence on SMSI.

In earlier investigations of motion sickness $[14,21,24 \mathbf{j}$, the incidence of motion sickness (vomiting) was found to increase by a factor approximately proportional to the square root of time.
Those studies used a relativity high and uniform acceleration level, but this study used fairly low and intermittent provocation levels with frequent pauses, for example, when passing a station at low speed or on longer stretches of straight track. Therefore, the subjects were possibly able to recover at the lower provocation levels. Golding et al. [13] showed that subjects report recovery times of 5-10 min of total rest after a $30-\mathrm{min}$ test run with horizontal acceleration. The higher SMSI reported from the first and last part (in the current tests) probably indicates that this part of the track is more severe (nauseogenic) than the other part. This also means that the results (SMSI) from different test parts are more or less independent from each other, because the subjects recovered from earlier motion doses. Different tracks (up and down line) may influence this further.

The effects of curve radius have not been investigated explicitly, because yaw acceleration has not been measured. Izu et al. [19] reported that the nauseogenic effect of cross-coupled rotation is proportional to gyroscopic angular acceleration. Gyroscopic acceleration is defined [19] as $G_{a c c}=-\Psi \times \Phi$, where $\Psi$ is rotation about an earth-vertical axis (yaw) and $\Phi$ is roll velocity. For a tilting train, the roll velocity in a transition curve has a magnitude of typically $3-4 \%$. The corresponding yaw acceleration has a level of $0.8-1.3 \% \mathrm{~s}^{2}$ and on circular curves yaw speeds of about $2.8-4.1 \%$ s. The values given depend on the radius of curve; lower values correspond to a radius of about $1000 \mathrm{~m}$ and the higher values to about $500 \mathrm{~m}$. This means that on smaller radius curves, the radial nauseogenic effect of cross-coupled rotation is amplified and may become a problem. The published papers from Japan $[27,36]$ do not mention this potential contribution as an explanation of motion sickness in tilting trains, but it may be important.

Conditions $\mathrm{F}$ and $\mathrm{G}$ both used a $55 \%$ degree of compensation, 
with the difference that condition $\mathrm{F}$ had a limitation on tilt acceleration and $G$ had a limitation on tilt speed. Despite the fact that roll acceleration motion dose correlates well with SMSI, the condition $\mathrm{G}$ indicates a lower SMSI than condition $\mathrm{F}$, although not statistically significant. A limitation of the tilt acceleration means that the tilt acceleration has to have a longer duration to achieve the necessary tilt speed. If the tilt motion cannot start before the transition curves is detected, this means also that the tilt speed has to increase to complete the tilt motion in time. The roll acceleration motion dose can in this case be increased despite a limitation of tilt acceleration because of the needed higher tilt speed.

The field of vision is probably of great importance for modifying the nauseogenicity of motions [25]. Because the subjects were able to look out of the windows, they were able to view a horizon to stabilize their reference perception. Rolnik and Bles [31] showed that an artificial horizon or a visual reference through windows can reduce motion sickness symptoms and performance decrement while working in a closed tilting room. In this study, the decrease in SMSI among women traveling backward is possibly due to this factor, because it is probably easier find an object to focus on when riding backward.

The activity (working, reading, talking) reported by the subjects does not seem to correlate with SMSI, although some subjects reported that if they had been reading for a while they had to stop this activity because of nausea. The correlation between the subjects' reported subjective sensitivity of motion sickness and the reported SMSI seems quite good. However, the men seemed to overestimate their sensitivity and women underestimate theirs at the self-estimated sensitivity of 3 to 5 according to Fig. 6 .

\section{CONCLUSIONS}

This study has evaluated SMSI experienced by healthy subjects in a high-speed train using active tilting of the car body on a curve to reduce lateral acceleration. On average, the subjects found the average ride comfort in all test conditions to be good. By using a lower degree of compensation (55\%) instead of the normal $(70 \%)$, a reduction of up to $25-40 \%$ in the number of test persons reporting SMSI was found. A limited tilt speed instead of a limited tilt acceleration probably gives a higher reduction of SMSI. Inadequate compensation levels may create ride discomfort due to high lateral acceleration levels and a high rate of change of lateral acceleration. The female subjects reported two to three times as many symptoms as the males or about $12 \%$ higher SMSI for all conditions. SMSI values, evaluated over a suitable length of time or track, seems to be approximately proportional to motion dose of roll acceleration.

The absolute levels of SMSI found are probably not directly transferable to a normal population of train passengers because of the selection of subjects (sensitivity, age, etc.). However, it is likely that lower compensation and limited tilt speed also are favorable in a more normal population of passengers.

\section{FUTURE RESEARCH}

Future research should analyze the influence of lateral and vertical accelerations, in addition to roll speed and roll acceleration, on motion sickness. This should make it possible to minimize complaints of discomfort and thereby enhance ride comfort and ability to work on future high-speed tilting trains.

\section{ACKNOWLEDGEMENTS}

Supported by the Swedish State Railways (SJ), Adtranz Sweden, the Swedish Transport and Communications Research Board (KFB) and the Swedish National Road and Transport Research Institute (VTI). The test runs were financed by SJ and supported by Adtranz Sweden. To all test subjects we owe appreciation for their willingness and consent to participate in the test.

\section{REFERENCES}

1. AGARD. Motion sickness: Significance in aerospace operations and prophylaxis. AGARD, Neuilly sur Seine, 1991.

2. Andersson, E.; Nilstam, N. The development of advanced high speed vehicles in Sweden. Proc. Inst. Mech. Eng. D 198:229-237; 1984.

3. Andersson, E.; von Bahr, H.; Nilstam, N. G. Allowing higher speed on existing tracks-design considerations of train X2000 for Swedish state Railways (SJ). Proc. Inst. Mech. Eng. F. J. Rail Rapid Trans. 209:93-104; 1995.

4. Benson, A. J. Motion sickness. In: Ernsting, K., ed. Aviation medicine. Lomen: Butterworths; 1988:318-338.

5. BSI. British standard guide to measurement and evaluation of human exposure to whole-body mechanical vibration and repeated shock. London: British Standards Institution; 1987.

6. CEN. Railway applications. Ride comfort for passengers. Measurement and evaluation. Brussels: CEN; 1995

7. Chappel, T. Passenger comfort test (APT) of April 1984: planning and conduct. Derby: British Rail Research; 1986.

8. Crampton, G. H. Motion and space sickness. Boca Raton, FL: CRC Press; 1990.

9. Förstberg, J. Comfort disturbances caused by low-frequency motions in modern trains. Linköping, Sweden: VTI; 1994.

10. Förstberg, J. Comfort disturbances caused by low-frequency motions in modern trains. Proceedings WCRR '94, SNCF, Paris, 1994, pp. 1135-1137.

11. Förstberg, J. Motion-related comfort levels in trains: a study on human response to different tilt control strategies for a high speed train. Stockholm: Railway Engineering, KTH; Linköping; VTI; 1996:66.

12. Förstberg, J.; Ledin, T. Discomfort caused by low-frequency motions. A literature survey of hypotheses and possible causes of motion sickness. Linköping; VTI; 1996

13. Golding, J. F.; Markey, H. M.; Stott, J. R. R. The effects of motion direction, body axis, and posture on motion sickness induced by low frequency linear oscillation, Aviat. Space Environ. Med. 66:1046$1051 ; 1995$

14. Griffin, M. J. Handbook of human vibration. London: Academic Press; 1990.

15. Griffin, M. J. Physical characteristics of stimuli provoking motion sickness. AGARD Lecture Series 175, AGARD, Neuilly sur Seine, 1991.

16. Harborough, P. R. Passenger comfort during high speed curving. Summary report. Derby: British Rail Research; 1986.

17. Harborough, P. R. Passenger comfort during high speed curving: analysis and conclusions. Derby: British Rail Research; 1986.

18. ISO. Mechanical vibration and shock-evaluation of human exposure to whole body vibrations. Part 1. General requirements. Geneve: ISO; 1997.

19. Izu, N.; Yanagihara, M.-A.; Yoneda, S.; Hattori, K.; Koo, J. The severity of nauseogenic effect of cross-coupled rotation is proportional to gyroscopic angular acceleration. Aviat. Space Environ. Med. 67: 325-332; 1996

20. Kufver, B. Variables and criteria for evaluation of vehicles reactions caused by railway alignment. Stockholm: KTH; 1997.

21. Lawther, A.; Griffin, M. J. Prediction of the incidence of motion sickness from the magnitude, frequency, and duration of vertical oscillation. J. Acoust. Soc. Am. 82:957-966; 1987.

22. Lawther, A.; Griffin, M. J. A survey of the occurrence of motion sickness amongst passengers at sea. Aviat. Space Environ. Med. 59: $399-406 ; 1988$.

23. Magnusson, M.; Örnhagen, H. Rörelsesjuka-sjösjuka. Översikt och utvecklingslinjer. Sundbyberg: FOA; 1994.

24. McCauley, M. E.; Royal, J. W.; Wylie, C. D. Motion sickness incidence: exploratory studies of habituation, pitch and roll, and the refinement of a mathematical model. Goleta, CA: Human Factors Research Inc; 1976.

25. Money, K. E. Motion sickness. Physiol. Rev. 50:1-39; 1970. 
26. Money, K. E. Signs and symptoms of motion sickness and its basic nature. Motion sickness: significance in aerospace operations and prophylaxis. AGARD Lecture Series 175, AGARD, Neuilly sur Seine, 1991.

27. Ohno, H. What aspect is needed for a better understanding of tilt sickness? Q. Rep. RTRI 37:9-13; 1996.

28. Oman, C. M. Motion sickness: a synthesis and evaluation of sensory conflict theory. Can. J. Physiol. Pharmacol. 68:294-303; 1988

29. Reason, J. T. Motion sickness adaption: a neural mismatch model. J. R Soc. Med. 71:819-819; 1978.

30. Reason, J. T.; Brand, J. J. Motion sickness. London: Academic Press; 1975.

31. Rolnik, A.; Bles, W. Performance and well-being under tilting condi tions: the effects of visual reference and artificial horizon. Aviat. Space Environ. Med. 60:779-785; 1989.

32. Siegel, S.; Castellan, N. J. Nonparametric statistics for the behavioral sciences. 2nd ed. New York: McGraw-Hill; 1988.
33. Sperling, E.; Betzhold, C. Beitrag zur Beurteilung des Fahrkomforts in Scheinenfahrzeugen. Glasers Ann. 80:314-320; 1956.

34. Sussman, E. D.; Pollard, J. K.; Manger, P.; DiSario, R. Study to establish ride comfort criteria for high speed magnetically levitated transportation systems. Cambridge, MA: U.S. Dept. of Transportation; 1994.

35. Treisman, M. Motion sickness: an evolutionary hypothesis. Science 197:493-495; 1977

36. Ueno, M.; Ogawa, T.; Nakagiri, S.; Arisawa, T.; Mino, Y.; Oyama, K.; Kodera, R.; Taniguchi, T.; Kanazawa, S.; Ohta, T.; Aoyama, H. Studies on motion sickness caused by high curve speed railway vehicles. J. J. Indust. Health 28:266-274; 1986.

37. Wertheim, A. H.; Wientjes, C. J. E.; Bles, W.; Bos, J. E. Motion sickness studies in the TNO-TM Ship Motion Simulator (SMS). Soesterberg, Netherlands: TNO Human Factors Research Institute; 1995. 
VI FORSKAR FÖR ETT LIV I RÖRELSE

Statens väg- och transportforskningsinstitut (VTI) har kompetens och laboratorier för kvalificerade forskningsuppdrag inom transporter och samhällsekonomi, trafiksäkerhet, fordon, miljö samt för byggande, drift och underhăll av vägar och järnvägar.

The Swedish National Road and Transport Research Institute (VTI) has laboratories and know-how for advanced research commissions in transport and welfare economics, road safety, vehicles and the environment. It also has research capabilities for the construction, operation and maintenance of roads and railways.

\section{Adress}

Postal address

SE-581 95 Linköping, Sweden
Telefon

Telephone

Nat 013-20 4000

Int +4613204000
Fax

E-post

E-mail

Nat 013-14 1436

Int +4613141436 